\title{
KAJIAN LONGSOR AKIBAT GEMPA DI NAGARI TANDIKEK KECAMATAN PARTAMUAN KABUPATEN PADANG PARIAMAN SUMATERA BARAT, INDONESIA
}

\author{
A Saidi ${ }^{1), *}$, I Berd $^{2)}$, dan R Har $^{3)}$ \\ 1)F aculty of Agriculture, Andalas U niversity \\ 2)F aculty of Agriculture Technology, Andalas U niversity \\ 3)P ostgraduate Program, Andalas U niversity \\ ${ }^{*}$ Coresponding author: amrizal.saidi@gmail.com
}

\begin{abstract}
Earthquacke on 30th of September 2009 in West Sumatra had ruined Padang Pariaman, Agam, and Padang city districts. The damage was not only caused by the earthquake itself but also due to the landsliding following the earthquake, such as in Tandikek. Hundreds of people, houses, buildings, schools, as well as agricultural land (ricefield and dryland farming) were burried in Lubuk Laweh, Kepala Koto and Cumanak. This research was conducted by employing survey method and by observing the phenomenon of tuff pumice on how it was affected by earthquake and water. Then, soil characteristics were analysed based on soil physical data from previous research. Several soil characteristics analysed were soil texture, bulk density, structure and depth of solum, organic matter content, and permeability. Land characteristics were determined through field visit. Some land condition being observed was slope (percentage and length), stone exposed, soil water depth, and land use. Additionally, besides from field visit, the data were also obtained from topography and morphology maps derived from Google Earth. Rainfall data (monthly and annually) were collected from several nearby meteorology stations. Analyses for degree of landsliding risks for an area were used soil and land characteristics criteria causing landsliding. Based on field visit, it was seen that the research area was still susceptible to landsliding. This was due to the parent materials of the soil deriving from tuff pumice which is crumb structure and loamy texture on the top layer. Climate, especially annual rainfall in study site was high enough (approximately $4322 \mathrm{~mm}$ ) which was evently distributed all year long without dry month. Slope of the area was $>45 \%$, especially areas hit by landsliding. Land use was not based on soil conservation rule, such as coconut and arenga pinneca, and other mixed trees were planted on the area having $>45 \%$ slope. The results of the soil characteristic analyses showed that HARKAT interval of lansliding threat was 13 and land characteristics showed 20. Summation of HARKAT values from soil and land characteristics was 33. This number showed that the study site had high degree of landsliding risk. The possibility of areas would be hit by lansliding were Partamuan, Koto Timur, Sungai Geringging, and around Maninjau lake.
\end{abstract}

Keywords : earthquake, soil and land characteristics, tuff pumice, wet tropical

\section{PENDAHULUAN}

Gempa dahsyat 7,9 SR yang terjadi pada hari Rabu tanggal 30 September 2009 berpusat di Samudra Hindia $57 \mathrm{~km}$ sebelah Barat Daya Pariaman dengan kedalaman 71 $\mathrm{km}$ mengakibatkan lumpuh sebagian Ranah Minang dengan kerusakan yang cukup parah bagi Kabupaten Padang Pariaman, Kota Padang, Pesisir Selatan, kabupaten Pasaman dan Kabupaten Agam. Gempa tersebut telah menelan korban jiwa sekitar 1000 jiwa dan merusakkan rumah, lahan pertanian seperti sawah, sarana irigasi, korban binatang ternak sekitar 650 ternak dan sebagainya. (Taufik Efendi)

Menurut Kepala Dinas Pertanian Sumatera Barat (Singgalang 14 Oktober 2009), gempa telah merusakkan 88 unit saluran irigasi dan mengakibatkan 10592 ha sawah kekeringan, setengah dari luas tersebut berada di kabupaten Padang Pariaman (5747 Ha). Selanjutnya Menurut Badan Nasional Penanggulangan Bencana 
(BNBP) merekapitulasi dampak gempa sebesar 88 kerusakan saluran irigasi ( 40 rusak berat, 24 rusak sedang, dan 22 rusak ringan. Dari kerusakan saluran tersebut terdapat 45 buah saluran irigasi di Kabupaten Pasaman Barat ( 14 rusak berat, 17 rusak sedang, 14 rusak ringan). Sedangkan kabupaten Mentawai 11 rusak berat. Kota Padang mencapai kerusan irigasi sebanyak 7 buah, kabupaten Agam kerusakan saluran 5 buah, kabupaten Solok hanya 1 saluran rusak. Disamping itu, gempa juga mengakibatkan sekitar 170 ribu orang kehilangan pekerjaan. Jika kondisi tidak segera diperbaiki tentu akan mengancam hasil pertanian masyarakat dan mengancam ketahanan pangan Sumatera Barat.

Kerusakan sarana dan prasarana perekonomian serta kerusakan sarana sarana irigasi, distribusi sarana produksi pertanian melumpuhkan perekonomian masyarakat selama beberapa bulan bahkan beberapa tahun mendatang. Oleh sebab itu perhatian terhadap upaya rehabilitasi dampak gempa ini segala aspek perlu dilakukan secepatnya agar supaya kebangkitan perekonomian masyarakat dapat pulih kembali, walaupun membutuhkan biaya yang besar namun tetap harus diupayakan. Kerusakan yang terberat akibat gempa adalah kabupaten Padang Pariaman, disamping rumah rusak, sarana prasarana pertanian, juga kebun dan persawahan tertimbun oleh longsoran yang berskala besar yang diperkirakan sebesar 1.000.000 m3 bahan longsoran menimbun kampung dan persawahan.

Dampak gempa terhadap lahan pertanian disebabkan oleh terjadi tanah tanah longsor dan pada waktu hujan terjadi erosi yang berat sehingga lahan pertanian terdegradasi sehingga menurunkan produktivitas sumberdaya alam. Hal ini akan mengakibatkan lahan pertanian menjadi tidak berfungsi walaupun perhatian mempertahankan lahan kering didorong oleh kesadaran akan perlunya sumberdaya daya alam dari ancaman erosi, serta pengamanan daerah hilir dari pengendapan berlebihan dan banjir. Kerusakan akibat longsoran yang dipicu oleh gempa tersebut terjadi di kenagarian
Tandikek kecamatan Partamuan.

Tandikek Kenagarian Tandikek terletak di Kecamatan Patamuan Kabupaten Padang Pariaman berada $59 \mathrm{~km}$ di Utara kota Padang dan $16 \mathrm{~km}$ di Timur kota Pariaman dan dilalui oleh sungai Batang Mangau yang mengalir dari Malalak melintasi gunung Tandikek, Bukik Gunuang Tigo dan Bukik Lubuak Laweh mengalir sepanjang $46 \mathrm{~km}$ ke hilirnya, dengan debit aliran antara 8-15 $\mathrm{m}^{3} /$ detik. Penggunaan lahan kenagarian Tandiek terdiri dari hutan $624 \mathrm{Ha}$, semak belukar $29 \mathrm{Ha}$ dan lainnya berupa kebun campuran dan kampung. Curah hujan rata-rata tahunan sekitar 4322 $\mathrm{mm} /$ tahun.

Kenagarian Tandikek terdiri dari 11 Korong (Desa), dimana 3 Desa diantaranya Cumanak-Paraman, Lubuak Laweh dan Kepalo Koto yang terparah mengalami bencana longsor akibat gempa bumi terjadi pada 30 September 2009 jam 17.15 WIB berkekuatan 7,9 diambang malam memilukan tersebut. Lonsoran ini berasal dari lereng Bukik Gunuang Tigo dan Bukik Lubuk Laweh disisi Utara Desa yang menewaskan lebih dari 200 jiwa tertimbun disana

Aliran sungai Batang Mangau telah ikut menghanyutkan tanah batu apung (Tuff Pumice) dari longsoran yang berskala besar lainnya terjadi dibagian hulu DAS batang Masang kiri, DAS batang Nareh dan DAS batang Mangau. Desa Tandikek yang mengalami longsor besar tersebut memang berada di DAS Batang Mangau. Disebelah Utara Kenagarian Tandikek terdapat jajaran Bukik Gunuang tigo, Bukik Lubuak Laweh dan dibelakangnya terdapat gunung Tandikek, dari sana mengalir sungai Bantang Mangau. Vegetasi penutup lahan yang dominan adalah hutan, kayu manis, karet, kelapa, pinang, pakis, krinyu, kebun campuran dan sawah.

Gunung Tandikek merupakan salah satu gunung api yang masih aktif dengan formasi geologi tufa vulkanik dan jenis tanah andisol. Lahan disekitar kawasan Gunung Tandikek masih tergolong lahan dengan tingkat kesuburan yang tinggi karena mendapat limpahan abu vulkanik dan menjadi sumber unsur hara, sehingga daerah 
ini merupakan wilayah produktif untuk pertanian.

Lokasi longsor di desa Palo-Koto, Paraman-Cumanak dan Lubuk Laweh, bermukim penduduk lebih kurang 850 jiwa yang hidup terutama dari usaha pertanian. Dilokasi inilah tertimbun ratusan jiwa oleh longsoran dari bukit yang ada disebelah Utara perkampungan penduduk tersebut.

Longsoran yang terjadi berbahan batu apung sebagai bahan induk dari perbukitan tersebut. Gempa bumi telah melongsorkan bahan tanah yang kaya dari batuan induk batu apung lebih dari $1.000 .000 \mathrm{~m}^{3}$ yang merupakan kategori longsor berskala besar.

Dari data klimatologi kepala Hilalang diketahui selama bulan September 2009, hujan cukup banyak terjadi, bahkan sehari sebelum gempa bumi hujan lebat terjadi dan disinilah bencana longsor terjadi, yang menelan korban jiwa manusia termasuk ternak dan menggusur vegetasi yang ada dilokasi ini.

Tingginya potensi bencana longsor di Padang Pariaman sebagaimana yang telah diungkapkan oleh hasil kajian Japanes International Cooperation Agency (JICA, 2009), dimana terdapat 126 titik lokasi berpotensi longsor dibeberapa Kecamatan di Kabupaten Padang Pariaman. Toshiasu Ueno menyatakan dalam Workshop JICA bahwa potensi longsor terjadi dikawasan Kaldera atau Tepi Kawah, Andesit dari Kaldera Danau Maninjau, tuf batu apung horenblenda hipersten dan didaerah ketinggian diatas $500 \mathrm{~m}$.

Bahan induk batu apung adalah bahan yang mudah lepas dan dihanyutkan oleh air. Hujan yang terjadi akan mengisi ruang pori mikro dan makro tanah pegunungan tersebut dan dengan bencana gempa bumi akan menyebabkan tanah pada lereng perbukitan ini akan berpotensi melepaskan lapisan tanah yang terpicu gerakan gempa bumi oleh gaya gravitasi yang ada dan beban beratnya volume yang jenuh air tersebut

Berdasarkan uraian diatas, fenomena tanah longsor ini mungkin akan terjadi lagi pada masa yang akan datang, maka untuk itu diperlukan penelitian untuk mempelajari bahan induk apung dalam hubungannnya dengan kerawanan terjadinya tanah longsor lanjutan di daerah Tandikek ini.

Penelitian bertujuan untuk meneliti fenomena batua apung yang mempengaruhi terjadi proses tanah longsor di Tandikek. Kemudian penelitian juga bertujuam untuk meneliti upaya yang mungkin dapat dilakukan untuk memperbaiki kondisi fisik tanah ini agar tidak peka lagi terhadap bahaya longsoran.

\section{BAHAN DAN METODA}

Peneltian dilakukan di Kenagarian Tandikek, kecamatan Pertamuan, kabupaten Padang Pariaman. Analisis tanah dilakukan pada jurusan Tanah Fakultas Pertanian Unand. dan Analisis air dilakukan pada UPTD Balai Laboratorium Kesehatan Propinsi Sumatera Barat.

Penelitian dilakukan dengan menggunaakan metoda survei yaitu melakukan penjelajahan ke lapangan dan melihat penomena bahan tufa batuapung dipengaruhi oleh air. Disamping itu untuk data analisis karakteristik tanah menggunakan data sifat fisik tanah yang yang telah diperoleh oleh mahasiswa kita yakni tekstur tanah menggunakan metoda pipet dan ayak, bobot isi dengan metoda gravimetrik, struktur dan kedalaman solum tanah diamati dengan meneliti langsung dari tanah yang terungkap di lapangan, kandungan bahan organik dengan metoda walkley dan Black, dan permeabilitas tanah dengan menggunakan metoda Debot dan Gabriel. Selanjutnya untuk menganalisis karateristik lahan dilakukan dengan mengamati ke lapangan yakni berupa kemiringan lahan, panjang lereng, singkapan batuan, kedalaman muka air tanah dan penggunaan lahan. Disamping itu juga dibantu dengan menggunakan peta topografi dan geomorfologi yang diambil dari peta Google earth. Data curah hujan dikumpulkan dari stasion hujan yang terdekat yaitu berupa jumlah curah hujan tahunan dan hulanan. Analisis pengolahan data menggunakan kriteria Zuidam (1979); Daekombe dan Gardiner (1983) dan Dookamp (1994). 
Analisis kejadian longsoran juga diamati di lapangan dengan menggunakan bagaimana rapuhnya bahan induk tufa batuapung terhadap daya perusak air . Data diperlihatkan dengan gambar dari hasil dua waktu pemotretan selang waktu 21 hari.

\section{HASIL DAN KESIMPULAN}

\section{Keadaan Umumn Daerah Studi}

Secara geografis lokasi studi Tandikek terletak pada $0^{\circ} 28^{\circ} \mathrm{LS}$ sampai 0o $33^{\circ} \mathrm{LS}$ dan $100^{\circ} 09^{\circ}$ sampai $100^{\circ} 18^{\circ} \mathrm{BT}$. Letak daerah secara administrasi berada di kenagarian Tandikek, kecamatan Partamuan, kabupaten Padang Pariaman, Proponsi Sumatara Barat. Lokasi studi berjarak sekitar $59 \mathrm{~km}$ dari kota Padang dan $19 \mathrm{~km}$ dari kota Pariaman. Letak lokasi dapat dilihat pada Gambar 1.

Lokasi nagari Tandikek merupakan kaki gunung Tandikek arah ke Barat dengan mengalir batang Mangau yang membelah nagari tersebut. Pada waktu gempa dan longsor terjadi bahan tanah yang terkena longsor menimbun sungai batang mangau sehingga beberapa jam tidak ada aliran air ke bawah dan air menggenang di atas karena sungai terhempang oleh bahan longsoran yang besar.

\section{Iklim}

Unsur iklim yang berperan terhadap frekuensi terjadi longsoran pada lahan baik lahan pertanian maupun lahan pemukiman. Unsur iklim yang besar pengaruhnya adalah data curah hujan, hari hujan dan intensitas hujan. Disamping itu data suhu, kelembaban udara, radiasi, lama penyinaran matahari, kecepatan angin dan penguapan diperlukan untuk menentukan evapotranspirasi harian dan bulanan serta menentukan neraca air bulanan di daeah studi.

Jumlah curah hujan sebanyak 4322 $\mathrm{mm} /$ tahun dengan penyebaran curah hujan merata sepanjang tahun (171 mm - $603 \mathrm{~mm}$ ) dengan tidak ada bulan kering, hari hujan dan curah hujan tertinggi daerah studi mempunyai curah hujan hampir. Jadi ketersediaan air tidak membatasi bagi pertumbuhan tanaman namun ada kemungkinan terjadi pencucian hara ke lapisan bawah akibat curah hujan yang tinggi tersebut disamping bentuk lahannya berupa daerah dataran rendah. (Stasion Klimatologi Sicincin, 2006).

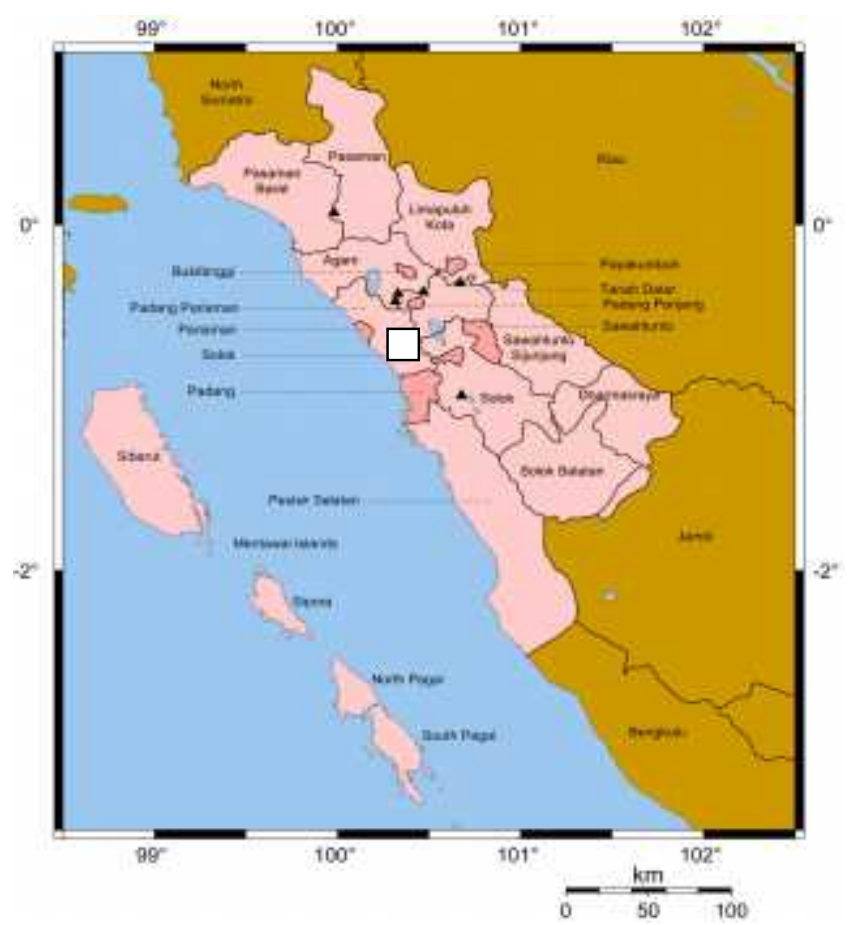

Gambar 1. Lokasi daerah Padang Pariaman 
Berdasarkan dari data curah hujan bulanan, dan klasifikasi iklim menurut Oldeman, daerah studi dapat digolongkan pada zona agroklimat A (Oldeman, Irsal Las dan Darwis ; 1979), tipe A (Smith dan Fergusson, 1957) dan Tipe Af (Koppen). Suhu udara maksimum berkisar dari 30,9 sampai $31,8{ }^{\circ} \mathrm{C}$, suhun minimum, berkisar dari 21.1 sampai $22,9{ }^{\circ} \mathrm{C}$ dan suhu rataan berkisar dari 24,0 sampai $26,4{ }^{\circ} \mathrm{C}$ serta kelembaban udara berkisar dari $82-89 \%$. Selanjutnya penyinaran matahari berkisar dari 8,1 sampai $69 \%$, kecepatan angin berkisar dari 0,3- 0,7 m /detik, dan tekanan udara berkisar dari 990,7 sampai 1002,6 milibar serta arah angin umumnya dari arah Barat Daya.

Neraca air adalah suatu kondisi yang menggambarkan tingkat perimbangan atau perbandingan jumlah antara air yang masuk dan yang hilang/keluar dalam suatu proses daur hidrologi. Secara umum neraca air dapat memberikan gambaran mengenai tinggi rendahnya fluktuasi air tanah yang tersimpan, dimana curah hujan yang jatuh melalui permukaan tanah akan meresap melalui pori-pori tanah dengan jalan infiltrasi maupun perkolasi, serta kehilangan lain melalui aliran permukaan. Evapotranspirasi merupakan komponen lain yang penting dalam penentuan neraca air.

Berdasarkan data suhu, penyinaran matahari, kelembaban nisbi dan kecepatan angin dengan menggunakan metoda AGLW/FAO dengan program Cropwat, maka nilai Evapotranspirasi (ET) Penman didapatkan yakni berkisar dari 92 sampai $113 \mathrm{~mm} / \mathrm{bulan}$

Penyusunan neraca air daerah studi dapat dilakukan dengan mengurangkan data curah hujan bulanan dengan evapotranspirasi Penman bulanan untuk stasiunstasiun yang terdapat pada lokasi studi Dusun Tangah Kabupaten Solok atau dari stasiun-stasiun yang dekat dari lokasi studi. Hasilnya dapat dilihat pada Tabel 2.7 dan Gambar 2.1.

Dari Gambar 2 terlihat bahwa daerah studi pada umumnya tidak terdapat bulan-bulan yang kekurangan air dalam setiap tahun, malah kelebihan curah hujan yang memungkinkan terjadinya erosi dan longsoran yang besar.
Geologi dan Bahan Induk

Berdasarkan peta geologi lembar Padang (Kastowo, Leo, Gafour dan Amin (1996) sebagian daerah ini terdiri dari bahan vulkanik hasil erupsi kaldera Maninjau yaitu berupa tufa batuapung hornblenda hiperstin (Qhpt) (warna ungu) yang seluruhnya berupa lapilli batuapung berukuran $2-10 \mathrm{~cm}$ yang mengandung horblenda dan hiperstin atau biotit, agak kompak berwarna puti atau kuning keabuan bagi bahan segar dan berwarna coklat dari bahan yang sudah melapuk dan tufa batuapung dan andesit (Qpt)(warna merah muda) yang berupa serabut gelas 5-80 \% fragmen batuapung putih berukuran 1-20 cm, agak kompak (lihat Gambar 2. peta Geologi) .

\section{Geomorfologi dan bentuk lahan}

Secara geomorfologi daerah ini merupakan daerah dataran vulkanik dan volkanis lereng bawah dengan kemiringan berkisar dari dari 16- $45 \%$, setempat terdapat lembah sungai yang merupakan hasil dari pengendapan sungai dengan pola pengendapan yang menyebar kekiri dan kekanan. Hal ini disebabkan bahan tanah yang bagian rapuk yang terdiri dari batu apung yang sangat rapuh Daerah ini merupakan sebagian daerah dataran berkemiringan 0 - $8 \%$ dan setempatsetempat yang agak ke hulu sungai Mangau berkemiringan terjal > $45 \%$ yaitu gunung tiga, gunung tandikek dan bukit lubuk laweh. Bukit bukit ini tertinggal karena bahan lebih kompak dibandingkan dengan daerah sekitarnya, namun vegetasinya sebagian besar berupa kebun kelapa dan diselingi oleh campuran dengan pohon pinang dan tanaman lain. Wilayah ini merupakan daerah yang rawan longsor. Selanjutnya daerah sekitar kerucut gunung Singgalang dan Tandikek juga mempunyai kemiringan lahan yang terjal dan curam ( dengan kemiringan lahan > $45 \%$ ) dan juga rawan terhadap terjadinya longsoran, apalagi digoyang oleh gempa pada 30 Sepetember 2009 dan gempa-gempa selanjutnya yang sering terjadi akhir-akhir ini. Pada tanggal 7 April juga terjadi longsoran pada banyak tempat sehingga jalur Padang Bukitinggi terputus pada 20 titik longsor. Wilayah yang lebih bawah dari kaldera Maninjau dan 


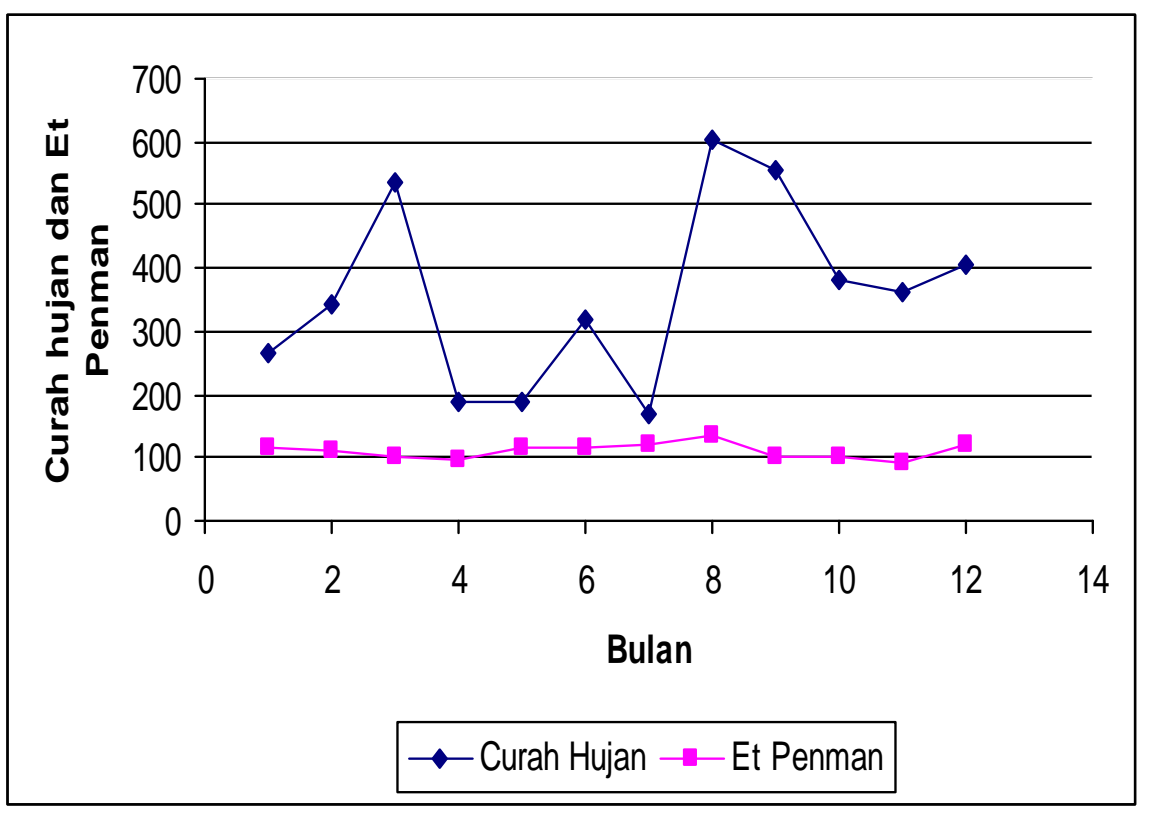

Gambar 2. Neraca air daerah studi Tandikek

volkanik lereng tengah mempunyai kemiringan 25- $45 \%$ dengan diselingi oleh perbukitan kecil dan mempunyai kermiringan lebih curam karena tertoreh oleh erosi air.

Selanjutnya daerah yang lebih bawah dengan kemiringan 16- $25 \%$ merupakan daerah bergelombang dan juga merupakan daerah tertoreh oleh erosi dan kadangkala tertoreh lebih dalam sehingga terdapat anak sungai dengan tebing yang curam.

\section{Jenis Tanah}

Berdasarkan pata satuan lahan Lembar Padang dari dari Pusat Penelitian Tanah Bogor Agroklimat (1990) terlihat bahwa satuan lahan daerah ini yang dominan terjadi longsor terdiri dari dua satuan lahan yakni

a. Satuan lahan Vd 232 dan Vd 233 yaitu dataran volkan dan plato dari bahan tuff masam pada daerah bergelombang (lereng 8-16\%), cukup tertoreh- sangat tertoreh, terletak pada ketinggian 40 - 700 meter dari permukaan laut. Jenis tanah dominan adalah Dystropept yangmeliputi luas 23556 ha atau $4,06 \%$ dari luas peta. Satuan lahan ini tersebar di daerah hulu Batang Ampalu. b. Satuan lahan Vd 2.7.2 dan Vd 2.7.3 yaitu dataran volkan dari bahan tuff intermedier dan lava dengan bentuk lahan perbukitan kecil (lereng > 16 $\%$ ), cukup tertoreh sampai sangat tertoreh yang teerdapat pada ketinggian 50 - 495 meter dari permukaan laut. Jenis tanah Dystrandept meliputi luas 6540 ha (1,13\%). Satuan lahan Vd 273 tersebar di daerah kecamatan sungai geringging yang rawan longsor. Satuan lahan Vd 272 terdapat di palao koto, lubuk cumanah, padang laweh yang merupakan daerah yang terjadi longsor di Tandikek yang dipicu oleh gempa 7,9 SR.

c. Satuan lahan Vab 2.10 .2 .yaitu berupa perbukitan volkan dari bahan tuff intermedier dan lava pada daerah berbukit (lereng > 16 $\%$ )cukup tertoreh, terdapat pada ketinggian $100-2300$ dari permukaan laut. Jenis tanahnya adalah Dystropept yang meliputi luas 34689 ha atau 5,99\% dari luas daerah. Lahan ini berupa berntuk lahan berbukit dan bergunung yang berada mulai pada kaki gunung Tandikek dan Singgalang .

d. Satuan lahan Vd 2.10.2. yaitu berupa yaitu berupa perbukitan 
volkan dari bahan tuff masam pada daerah berbukit (lereng > $16 \%$ ), cukup tertoreh, terdapat pada ketinggian $100 \quad-300$ dari permukaan laut. Jenis tanahnya adalah Humitropept yang meliputi luas 1021 ha atau $0,18 \%$ dari luas daerah

\section{Analisis Longsoran}

Bencana tanah longsor yang terjadi di sumatera Barat sudah menjadi tahap siaga, karena sering terjadi, seperti di Tandikek (30 Sepetember 2009) , di Payakumbuh, kecamatan, Lembah Anai sehingga memutskan jalan Padang Bukitiinggi dan banyak lain di luar Sumatera Barat, seperti di Madina (kabupaten Mandahiling Natal (propinsi Sumatera Utara), Bogor, Tawangmangu, dan Bogor dan lainnya.

Bencana tanah longsor di Tandikek ini dipicu oleh gempa pada tanggal 30 September 2009, sehingga menelan korban jiwa yang banyak yaitu sekitar 400 jiwa. Tanah longsor merupakan gerakan tanah yang menuruni lereng yang disebabkan oleh gaya gravitasi dan dalam prosesnya dipengaruhi oleh curah hujan yang tinggi, pola penmggunaan lahan yang tidak sesuai, batuan induk yang rapuh, serta sifat fisik tanah yang kurang baik. Menurut Zuidam (1979) proses terjadinya longsor dicirikan oleh karateristik tanah ( solum tanah, tekstur tanah, strutkur tanah, kandungan bahan organik tanah, bobot isi tanah serta permeabilitas tanah ) dan karateristik lahan seperti kemiringan lahan, panjang lereng, singkapan batuan, kedalaman muka air tanah, penggunaan lahan, dan curah hujan. Kriteria karateristik tanah dan lahan dapat dilihat pada Lampiran 1 dan 2.

\section{Karateristik Tanah}

a. Solum tanah

Jenis tanah yang terdapat didaerah Tandikek ini umumnya adalah dystropept dan dystrandep yang mempunyai solum tanah bervariasi tergantung kepada kemiringan lahannya. Pada lereng $25-45 \%$ umumnya mempunyai solum sedang ( 60 $90 \mathrm{~cm}$ ). Sedangkan pada daerah berelereng $>$ $45 \%$ umumnya mempunyai solum dangkal $(20-60 \mathrm{~cm})$. Jadi harkat kelasnya adalah 2

b. Tekstur tanah

Kondisi tekstur tanah di daerah Tandikek pada lapisan atas tergolong lempung sampai lempung berdebu. Hasil penentuan tekstur tanah di daerah Tandikek dapat dilihat pada Tabel 1. Dari Tabel 1 terlihat bahwa tekstur tanah lapisan atas umumnya tergolong lempung berdebu , maka harkat kelasnya tergolong 3 .

c. Struktur tanah

Penetapan struktur tanah dilakukan dengan menggunakan lup yaitu melihat bentuk struktur tanah tersebut. Jenis tanah didominasi oleh Dystropept dan dystrandept mempunyai struktur tanah remah dan granuler pada lapisan atas dan tidak bertrukur pada lapisan bawah. Jadi harkat kelasnya adalah 2 dan 4 .

Tabel 1. Tekstur tanah pada berbagai penggunaan lahan di Tandikek

\begin{tabular}{lllllll}
\hline No & Penggunaan Lahan & $\begin{array}{c}\text { Pasir } \\
(\%)\end{array}$ & $\begin{array}{c}\text { Debu } \\
(\%)\end{array}$ & $\begin{array}{c}\text { Liat } \\
(\%)\end{array}$ & Kelas & Harkat \\
\hline 1 & Kebun Campuran & 16 & 73 & 11 & Silt loam & 3 \\
2 & Sawah (Swh) & 24 & 74 & 2 & Silt loam & 3 \\
3 & Hutan (H) & 27 & 57 & 16 & Silt loam & 3 \\
4 & Kulit Manis & 22 & 75 & 3 & Silt loam & 3 \\
5 & Kebun Kelapa & 30 & 56 & 14 & Silt loam & 3 \\
\hline
\end{tabular}

Sumber : Yunita (2003) 
Tabel 2. Sifat Fisik tanah di bawah berbagai jenis penggunaan lahan

\begin{tabular}{|c|c|c|c|c|c|}
\hline No & $\begin{array}{l}\text { Jenis Penggunaan } \\
\text { Lahan }\end{array}$ & $\begin{array}{l}\text { Bobot Isi } \\
\left(\mathrm{g} / \mathrm{cm}^{3}\right) *\end{array}$ & Harkat & $\begin{array}{l}\text { Bahan } \\
\text { organik }(\%) \\
*\end{array}$ & Harkat \\
\hline 1 & K Campuran & 0.58 & 1 & 21,10 & 1 \\
\hline 2 & Sawah (Swh) & 0.42 & 1 & 18,92 & 1 \\
\hline 3 & Hutan $(\mathrm{H})$ & 0.44 & 1 & 20,81 & 1 \\
\hline 4 & Kulit Manis & 0.41 & 1 & 22,13 & 1 \\
\hline 5 & Kebun Kelapa & 0.57 & 1 & 19,62 & 1 \\
\hline
\end{tabular}

Sumber: *) Yunita (2003).

d. Kandungan bahan organik dan bobot isi

Kandungan bahan organik dan bobot isi dapat dilihat pada Tabel 2.

Dari Tabel 2. terlihan bahwa kandungan bahan organik di daerah Tandikek tergolong tinggi (> 5,01) yakni termasuk harkat 1 . Kemudian bobot isi juga tergolong pada harkat 1 yaitu kecil $0,75 \mathrm{~g} / \mathrm{cm} 3$.

e. Permeabilitas tanah

Nilai permeabilitas tanah untuk daerah studi Tandikek dapat dilihat pada Tabel 3. Dari Tabel 3. terlihat bahwa permeabilitas tanah di daerah studi tandikek agak bervariasi yakni berkisar dari 0,79 sampai sampai 11,29 yakni lambat sampai cepat (harkatnya 3 dan 4 khusus untuk penggunaan sawah, kebun campuran dan kebun kelapa.

Karakteristik Lahan

a. Kemiringan dan panjang lereng Berdasarkan peninjauan ke darah studi tandikek maka kemiringan lahan umumnya > $45 \%$ terutama untuk pengggunaan lahan hutan, kebun campuran, semak. Sedangkan panjang lereng tergolong panjang 50-250 m . Jadi harkat kemirngan lereng tergolong 4 dan panjang lereng tergolong 3 .

\section{b. Singkapan batuan}

Berdasrakan hasil peninjauan ke lokasi daerah longsor didapat singakapan batuan tergolong banyak dengan harkat 3 .

c. Kedalaman muka air tanah Berdasarkan hasil peninjauan ke lokasi studi Tandikek ternyata bahw kedalaman muka air tanah tergolong agak dangkal karena terdapat batuan masif di lapisan bawah yang merupakan bidang luncur bagi terjadinya longsor. Kedalaman muka air tanah tergolong harkat 3.

\section{Penggunaan lahan}

Jenis penggunaan lahan di daerah studi Tandikek seperti terlihat pada peta Gambar 5. Dari Tabel 2. dan Gambar 3 terlihat bahwa penggunaan lahan di daerah studi Tandikek umumnya di daerah lembah

Tabel 3. Nilai permeabilitas tanah di daerah studi Tandikek

\begin{tabular}{llclc}
\hline No & $\begin{array}{l}\text { Jenis Penggunaan } \\
\text { Lahan }\end{array}$ & $\begin{array}{l}\text { Permeabilitas } \\
(\mathrm{cm} / \text { jam })\end{array}$ & Jenis Tanah & Harkat \\
\hline 1 & K Campuran & 0.79 & Dystrppept & 4 \\
2 & Sawah (Swh) & 4.07 & Dystrppept & 3 \\
3 & Hutan (H) & 10.24 & Dystrandept & 1 \\
4 & Kulit Manis & 11.29 & Dystrandept & 1 \\
5 & Kebun Kelapa & 4.94 & Dystropept & 3 \\
\hline
\end{tabular}

Sumber: *) Yunita (2003). 


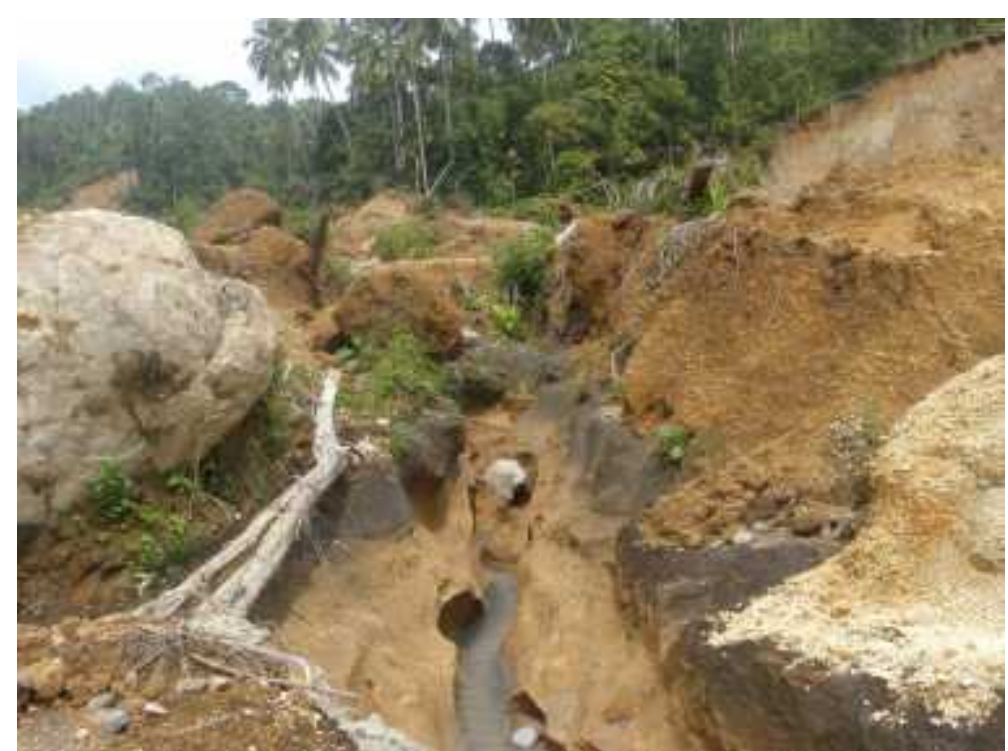

Gambar 3. muka air dangkal disebabkan lapisan bawah yang padat.

terdapat sawah, di daerah miring terdapat semak belukar dan kebun campuran dan kebun kelapa. Jadi dengan demikian berdasarkan kriteria, maka harkat penggunaan lahan tergolong semak dan kebun campuran adalah 2 dan 3 untuk sawah.

\section{Curah hujan}

Berdasarkan data curah hujan pada Tabel 2.1. terlihat bahwa jumlah hujan di daerah studi berkisar dari $171 \mathrm{~m}$ ( bulanan terendah yakni Juli) sampai $605 \mathrm{~mm}$ (bulanan tertinggi yakni Agustus). Jadi karateristik curah hujan tergolong sangat tinggi dengan harkat 4.

Hasil Analisis Longsoran

Berdasarkan dari hasil uraian diatas dapat disimpulkan bahwa harkat kelas di daerah studi Tandikek dapat terlihat pada Tabel 4 dan Tabel 5. Jadi jumlah interval tingkat bahaya longsor dari karateritirk tanah dan karakteristik lahan adalah $13+20=33$. Berdasarkan kriteria interval tingkat bahaya longsor tergolong agak tinggi. Hal ini dapat dijelaskan bahwa tanah di daerah longsoran sangat rapuh sekali, sehingga aliran air dengan mudah menghanyutkan tanah pada

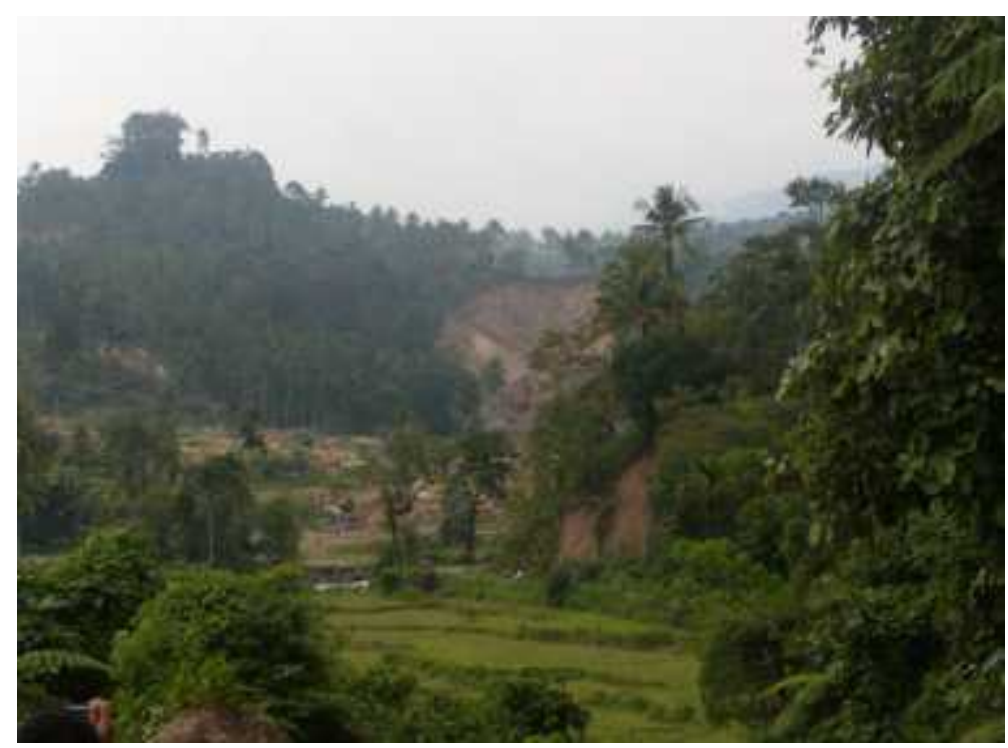

Gambar 4. Gambaran penggunaan lahan daerah Tandikek 
Tabel 4. Jumlah harkat karaklateristik tanah dan karakteristik lahan

\begin{tabular}{llllc} 
No & & Sifat Tanah & Keterangan & Harkat \\
\hline 1 & Solum & $25-60 \mathrm{~cm}$ & Dangkal & 2 \\
2 & Tekstur & L,SL,SiL,Si & Sedang & 3 \\
3 & Struktur & Berbutir tunggal, massive & Jelek & 4 \\
4 & C-Organik & $>5,01 \%$ & Sangat tinggi & 1 \\
5 & Bulk Density & $<0,75 \mathrm{~g} / \mathrm{cm} 3$ & Sangat baik & 1 \\
6 & Permebilitas & $2,0-6,25 \mathrm{~cm} /$ jam & Sedang & 3 \\
\hline & Jumlah & Karatersitik Tanah & & 13 \\
\hline
\end{tabular}

Tabel 5. Jumlah harkat karateristik lahan

\begin{tabular}{llllc}
\hline No & & Sifat Tanah & Keterangan & Harkat \\
\hline 1 & Kemiringan & $>40 \%$ & Curam & 4 \\
2 & Panjang lereng & $50-250 \mathrm{~m}$ & Panjang & 3 \\
3 & Singkapan batuan & $15-90 \%$ luas lahan & Banyak & 3 \\
4 & Kedalaman muka & $>100 \mathrm{~m}$ & Dangkal & 4 \\
& air & & & \\
5 & Landuse & Sm, Kc & Agak Baik & 2 \\
6 & Curah hujan & $>90$ mm/bulan & Sangat Tinggi & 4 \\
\hline & Jumlah & Karakteristik lahan & & 20 \\
\hline
\end{tabular}

Samping parit sehingga parit dengan mudah bertambah dalam hanya dengan waktu dua minggu sekarang erosi paritnya sudah menjadi dalam $100 \mathrm{~cm}$. Oleh sebab itu keadaan ini dikuatirkan akan mengakibatkan longsoran lain lagi jika paritnya bertambah dalam dengan waktu singkat. Kalau dilihat keadaan tanah di bagian samping parit terlihat bertekstur halus sampai sedang, sedangkan pada dasar parit tekstur lebih kasar karena bahan induk dibagian bawah yang lebih kasar dan ringan (berupa batu apung) dimana bahan ini mudah dihanyutkan oleh aliran air. Hal ini sesuaI dengan peta geologi daerah ini dari bahan batu apung ini tersebar di sebagian besar daerah kabupaten Pariaman ini (warna jambu air dari peta Geologi) (Qpt) dan batu apung negandung hornblenda dan hyperstin (Qhpt).

Oleh sebab itu bahaya longsor akan selalu terjadi di daerah ini ditambah curah hujan > $4000 \mathrm{~mm}$ pertahun terutama pada daerah berlereng terjal > $45 \%$ yang pada umumnya sudah ditanami dengan tanaman kelapa dan tanaman kebun campuran, lainnya. Apalagi diorong oleh adanya gempa pada 30 Sepetember 2009 dan gempa-gempa susulan. Kondisi ini mengakibatkan pada daetrah kaki gunung dan perbukitan selalu waspada karena goncangan gempa menyebabkan tanahnya retak dan pada waktu hujan, air memasuki celah retakan tersebut sehingga tanah lapisan atas yang jenuh dan pada lapisan bawah terdapat lapisan kedap air, sehingga merupakan bidang luncuran bagi terjadinya longsoran.

\section{KESIMPULAN DAN SARAN}

Kesimpulan

1. Daerah dengan bahan induk yang berasal dari tufa batuapung (Qtp) dan tufa batuapung hornblende hyperstin (QThp) atau berbahan 
induk vulkanis rawan terhadap longsor.

2. Daerah dengan kemiringan 25-60 $\%$ dan > $60 \%$ rawan terhadap longsoran.

3. Daerah studi termasuk kedalam harkat tingkat bahaya longsor yang tinggi.

4. Dampak longsoran telah menimbulkan kerugian lahan pertanian dan harta benda dan jiwa

5. Kerawanan daerah tandikek terhadap longsoran memerlukan kesiapsiagaan masyarakat dan tim penanggulangan bencana terutama pada saat hujan lebat.

Saran

1. Diperlukan penelitian lebih lanjut tentang daerah-daerah rawan longsoran di kabupaten Padang pariaman, kabupaten Agam dan Tanah Datar.

2. Diperlukan dicarikan upaya penanggulan daerah yang rawan longsor agar dapat mngurangi dampaknya .

3. Diperlukan penyuluhan kepada masyarakat dengan daerah-daerah yang rawan longsor agar mempersiapkan tim Siaga untuk mengurangi dampak longsoran.

\section{DAFTAR PUSTAKA}

1. Saidi A, dan Asmar (2003) Kajian Sifat Fisik dan Kimia Tanah di bawah beberapa jenis penggunaan Lahan di Lereng Gunung Tandikat. Padang Pariaman. Seminar HITI . Prosiding Seminar HITI. Padang 2224 Juli 2003.

2. Saidi,A (2010) Aspek Vegetasi dan penggunaan lahan dalam hubungan nya dengan degradasi dan peningkatan produktivitas tanah. Pidato Pengukuhan pada Tanggal 28 Januari 2010 di Rapat Senat Luar Biasa Unand Padang.

3. Dasrizal (2006) Analisis spasial distribusi dan tingkat bahaya longsor di Gunung Padang Sumatera Barat. Thesis Magister Sains pada Program Pascasarjana Unand Padang.

4. Yunita M (2003) Kajian sifat fisik tanah pada beberapa penggunaan lahan di daerah gunung tandikek Kabupaten Padang Pariaman. Skripsi pada Fakultas Pertanian Unand Padang.

5. Martayesa (2005) Pengakajian pengaruh kegiatan penambangan batu bintang (Obsidian) terhadap kandungan sedimen dan hara terangkut pada sub DAS Kalulutan.Kabupaten Padang Pariaman. Skripsi pada Fakultas Pertanian Unand Padang.

6. Kastowo, G W Leo, S. Gafour, and T.C.Amin (1996) Geological map of the Padang quadrangle, Sumatera Geological Research and Development Centre. Bandung

Lampiran 1. Kriteria penentuan karateristik tanah penyebab longsor

\begin{tabular}{|l|l|l|l|c|}
\hline No & & Sifat Tanah & Keterangan & Harkat \\
\hline 1 & Solum & $<25 \mathrm{~cm}$ & Sangat dangkal & 1 \\
\hline & & $25-60 \mathrm{~cm}$ & Dangkal & 2 \\
\hline & & $60-90 \mathrm{~cm}$ & Sedang & 3 \\
\hline & & $>90 \mathrm{~cm}$ & Dalam & 4 \\
\hline 2 & Tekstur & S & Sangat kasar & 1 \\
\hline & & LS,SiS,CS & Kasar & 2 \\
\hline & & L,SL,SiL,Si & Sedang & 3 \\
\hline & & C,SiC,SC & Halus & 4 \\
\hline 3 & Struktur & Remah & Sangat baik & 1 \\
\hline & & Granuler & Baik & 2 \\
\hline & & Gumpal, Lempeng, tiang & Sedang & 3 \\
\hline
\end{tabular}




\begin{tabular}{|l|l|l|l|l|}
\hline & & Berbutir tunggal, massive & Jelek & 4 \\
\hline 4 & C-Organik & $>5,01 \%$ & Sangat tinggi & 1 \\
\hline & & $3,01-5,0 \%$ & Tinggi & 2 \\
\hline & & $2,01-3,0 \%$ & Sedang & 3 \\
\hline 5 & & $<2,0 \%$ & Rendah & 4 \\
\hline & Bulk Density & $<0,75 \mathrm{~g} / \mathrm{cm} 3$ & Sangat baik & 1 \\
\hline & & $0,75-1,25 \mathrm{~g} / \mathrm{cm} 3$ & Baik & 2 \\
\hline & & $1,25-1,50 \mathrm{~g} / \mathrm{cm} 3$ & Sedang & 3 \\
\hline 6 & Permebilitas & $>12,5 \mathrm{gm} / \mathrm{jam} 3$ & Jelek & 4 \\
\hline & & $6,25-12,5 \mathrm{~cm} / \mathrm{jam}$ & Sangat cepat & 1 \\
\hline & & $2,0-6,25 \mathrm{~cm} / \mathrm{jam}$ & Cepat & 2 \\
\hline & & $<2,0 \mathrm{~cm} / \mathrm{jam}$ & Sedang & 3 \\
\hline
\end{tabular}

Sumber : Zuidam (1979): Daekombe dan Gardiner (1983); Cooke dan Doorkamp (1994).

Keterangan; $\mathrm{S}=$ Sang, LS = pasir berlempung, $\mathrm{SiS}=$ Pasir berdebu, CS = pasir berliat, L =Lempungberlempung: $\mathrm{SL}=$ lempung berpasir, $\mathrm{SiL}=$ Lempung berdebu, $\mathrm{Si}=$ debu, $\mathrm{C}=$ Liat - berliat, $\mathrm{SC}=$ liat berpasir, $\mathrm{SiC}=$ liat berdebu.

Lampiran 2. Kriteria Penentuan karateristik lahan penyebab longsor

\begin{tabular}{|c|c|c|c|c|}
\hline No & & Sifat Lahan & Keterangan & Harkat \\
\hline \multirow[t]{4}{*}{1} & Kemiringan & $0-13 \%$ & Datar-landai & 1 \\
\hline & & $14-25 \%$ & Mieing & 2 \\
\hline & & $26-40 \%$ & Agak curam & 3 \\
\hline & & $>40 \%$ & Curam & 4 \\
\hline \multirow[t]{4}{*}{2} & Panjang lereng & $<15 \mathrm{~m}$ & Pendek & 1 \\
\hline & & $15-50 \mathrm{~m}$ & Sedang & 2 \\
\hline & & $50-250 \mathrm{~m}$ & Panjang & 3 \\
\hline & & $>250 \mathrm{~m}$ & Sangat Panjang & 4 \\
\hline \multirow[t]{4}{*}{3} & $\begin{array}{l}\text { Singkapan } \\
\text { batuan }\end{array}$ & $<3 \%$ luas satuan lahan & Tidak ada, sedikit & 1 \\
\hline & & $3-15 \%$ & Sedang & 2 \\
\hline & & $15-90 \%$ & Banyak & 3 \\
\hline & & $>90 \%$ & Sangat Banyak & 4 \\
\hline \multirow[t]{4}{*}{4} & $\begin{array}{l}\text { Kedalaman } \\
\text { muka air }\end{array}$ & $>500 \mathrm{~m}$ & Dalam & 1 \\
\hline & & $250-500 \mathrm{~m}$ & Sedang & 2 \\
\hline & & $100-250 \mathrm{~m}$ & Agak Dangkal & 3 \\
\hline & & $<100 \mathrm{~m}$ & Dangkal & 4 \\
\hline \multirow[t]{4}{*}{5} & Landuse & $\mathrm{Ht}$ & Baik & 1 \\
\hline & & $\mathrm{Sm}, \mathrm{Kc}$ & Agak Baik & 2 \\
\hline & & $\mathrm{S}, \mathrm{Ut}$ & Sedang & 3 \\
\hline & & $\mathrm{P}$ & Jelek & 4 \\
\hline \multirow[t]{4}{*}{6} & Curah hujan & $>0-30 \mathrm{~mm} / \mathrm{bulan}$ & Rendah & 1 \\
\hline & & 30-60 mm/bulan & Sedang & 2 \\
\hline & & 60- $90 \mathrm{~mm} / \mathrm{bulan}$ & Tinggi & 3 \\
\hline & & $>90 \mathrm{~mm} / \mathrm{bulan}$ & Sangat Tinggi & 4 \\
\hline
\end{tabular}

Sumber : Zuidam (1979): Daekombe dan Gardiner (1983); Cooke dan Doorkamp (1994).

Keterangan $: \mathrm{Ht}=$ Hutan $; \mathrm{Sm}=$ Senak belukar, Kc = Kebun campuran; $\mathrm{S}=$ Sawah; Ut = tegalan; $\mathrm{P}=$ pemukiman 
Lampiran 3 . Interval tingkat bahaya longsor

\begin{tabular}{|l|l|l|}
\hline Kelas & Inteval & Tingkat Bahaya longsor \\
\hline I & $<18$ & Sangat Rendah \\
\hline II & $19-25$ & Rendah \\
\hline III & $26-32$ & Sedang \\
\hline IV & $33-39$ & Agak Tinggi \\
\hline V & $40-46$ & Tinggi \\
\hline VI & $>47$ & Sangat Tinggi \\
\hline
\end{tabular}

Sumber : Zuidam (1979): 


\begin{tabular}{|c|c|c|c|c|c|c|c|c|c|c|c|}
\hline 1 & 2 & 3 & 4 & 5 & 7 & 8 & 9 & 10 & 11 & 12 & 13 \\
\hline 14 & 15 & 16 & 17 & 18 & 19 & 20 & 21 & 22 & 23 & 24 & 25 \\
\hline 26 & 27 & 28 & 29 & 30 & 31 & 32 & 33 & 34 & 35 & 36 & 37 \\
\hline 38 & 39 & 40 & 41 & 42 & 43 & 44 & 45 & 46 & 47 & 48 & 49 \\
\hline 50 & 51 & 52 & 53 & 54 & 55 & 56 & 57 & 58 & 59 & 60 & 61 \\
\hline 74 & 75 & 76 & 77 & 78 & 79 & 80 & 81 & 82 & 83 & 84 & 85 \\
\hline 86 & 87 & 88 & 89 & 90 & 91 & 92 & 93 & 94 & 95 & 96 & 97 \\
\hline 98 & 99 & 100 & 101 & 102 & 103 & 104 & 105 & 106 & 107 & 108 & 109 \\
\hline 1 & 2 & 3 & 4 & 5 & 7 & 8 & 9 & 10 & 11 & 12 & 13 \\
\hline 14 & 15 & 16 & 17 & 18 & 19 & 20 & 21 & 22 & 23 & 24 & 25 \\
\hline 26 & 27 & 28 & 29 & 30 & 31 & 32 & 33 & 34 & 35 & 36 & 37 \\
\hline 38 & 39 & 40 & 41 & 42 & 43 & 44 & 45 & 46 & 47 & 48 & 49 \\
\hline 50 & 51 & 52 & 53 & 54 & 55 & 56 & 57 & 58 & 59 & 60 & 61 \\
\hline 74 & 75 & 76 & 77 & 78 & 79 & 80 & 81 & 82 & 83 & 84 & 85 \\
\hline 86 & 87 & 88 & 89 & 90 & 91 & 92 & 93 & 94 & 95 & 96 & 97 \\
\hline 98 & 99 & 100 & 101 & 102 & 103 & 104 & 105 & 106 & 107 & 108 & 109 \\
\hline 1 & 2 & 3 & 4 & 5 & 7 & 8 & 9 & 10 & 11 & 12 & 13 \\
\hline 14 & 15 & 16 & 17 & 18 & 19 & 20 & 21 & 22 & 23 & 24 & 25 \\
\hline 26 & 27 & 28 & 29 & 30 & 31 & 32 & 33 & 34 & 35 & 36 & 37 \\
\hline 38 & 39 & 40 & 41 & 42 & 43 & 44 & 45 & 46 & 47 & 48 & 49 \\
\hline 50 & 51 & 52 & 53 & 54 & 55 & 56 & 57 & 58 & 59 & 60 & 61 \\
\hline 74 & 75 & 76 & 77 & 78 & 79 & 80 & 81 & 82 & 83 & 84 & 85 \\
\hline 86 & 87 & 88 & 89 & 90 & 91 & 92 & 93 & 94 & 95 & 96 & 97 \\
\hline 98 & 99 & 100 & 101 & 102 & 103 & 104 & 105 & 106 & 107 & 108 & 109 \\
\hline
\end{tabular}

